\title{
Mutual recognition arrangements (MRAs) between France and Quebec: Innovating on the transnational professional front.
}

\author{
Jean-Luc Bédard \\ Professor, Téluq \\ ibedard@teluq.ca \\ 5800 St-Denis, bureau 1105 \\ Montréal (Québec) H2S 3L5 \\ Canada
}

Abstract: Mutual recognition arrangements (MRAs) are becoming increasingly frequent on the international scene, fostering enhanced professional mobility. This article focuses on the recent implementation of MRAs between France and Quebec, demonstrating how the political process played an important role in bringing organisations from both sides to reach arrangements that have allowed migrants faster access to professional practice in Quebec. The steps described highlight the complex yet ultimately feasible nature of such arrangements. Finally, this article raises several questions that will be addressed in an ongoing research project about French professionals entering the labour force in Quebec, with a focus on eight professions in particular.

Keywords: Mutual recognition arrangements, professions, immigrants, France, Quebec, immigration, access to professional practice, credentials, experience, mobility, regulations

In various regions of the world, initiatives are taken and policies such as mutual recognition arrangements are implemented to facilitate highly skilled migrants' access to professional practice (Iredale, 2000; Verdier, 2011). For migrants, access to professional practice entails becoming recognized by, and gaining entry into, their professional association, which grants them the right to hold their professional title and to work in that profession (within the legal parameters defined by local jurisdiction). Access to professional practice is granted when the official regulatory body recognizes a migrant's credentials; in the case of Quebec, the professional associations are such regulatory bodies. Depending on the profession's MRA and its specific rules, a migrant's path to full access to professional practice (when they can practice like their locally trained colleagues) may include various remedial training measures. These steps and measures are highly variable according to the professions and trades involved, and the length of time it takes to receive full access varies for each migrant's individual situation. Fees are also highly variable and structured in different ways from one profession to another. Moreover, the arrangements' structures sometimes offer "opting out" scenarios, for professionals for whom the MRA might not constitute a "fast track" scheme due to specific reasons. Therefore, each profession offers a path to full access that is highly complex, encompassing the various professional profiles that the candidates might hold (credentials, membership in a French professional association, and experience). Examples of these variations in costs, duration, and length of remedial training (if needed), are described below.

This article aims to describe how, in the case of the France-Quebec Agreement, these arrangements are organised and valued, and to identify the main questions that arise, by looking at the state of 8 different MRAs applied in Quebec since the official France-Quebec Agreement on the Mutual Recognition of Professional Qualifications was signed in 2008. The Quebec 
government's ruling body is the Office des professions du Québec; it oversees the legal context in which the professional system operates, with its 45 professional associations, 53 professions ${ }^{1}$ and 366000 members. These professional bodies are grouped into three broad categories by the Office: health and social services; engineering, urban planning and sciences; and law, administration and business. In our study of the MRAs for eight professions, we aim to treat these three categories as equally as possible. In the first category we will examine the MRAs for doctors (specialties to be defined), nurses, pharmacists, and social workers. In the second one, we will examine the trajectories of engineers (two specialties to be defined) and architects. The eighth group of professionals we will study are lawyers, from the third category.

The article takes a descriptive approach, with a few analytical perspectives and hypotheses, for two reasons. Firstly, barely any analyses exist yet of the various MRAs implemented between the two jurisdictions. Only one published document could be found (Mercier, 2012), other than official governmental publications that describe specific arrangements' objectives, their states of advancement, and the actors involved. As might be expected, there are a few analyses about to be published, namely about doctors ${ }^{2}$. But besides these upcoming publications, due to the relatively recent implementation of the MRAs the available documentation is mostly descriptive, and it offers only preliminary insights concerning the actual processes and results of the MRAs as experienced by French professionals immigrating to Quebec. Furthermore, some analysis has been drawn from a juristic, legal-studies perspective (Chaix, 2012; Houle \& Roux, 2012; Korotkina, 2012), pointing in particular to linkages between the Canadian Rights and Liberties Charter and access to professional practice for highly skilled migrants. These issues are not the focus of this article; moreover, apart from Chaix's contribution, these other analyses focus on immigrant workers in general, not specifically professionals nor those coming from France. Therefore, to our knowledge, there are no analyses examining migrants' access to professional practice and their experiences of the MRAs from the migrants' points of view.

Secondly, this article takes a descriptive approach because our own work on these MRAs is just beginning. This allows us to acknowledge the dearth of knowledge and to focus the article by summarizing the official structures of a few MRAs. Since these MRAs are reciprocal, Quebec professionals can encounter MRAs in France, but that process is beyond the scope of this article, which focuses on the Quebec side of the official Mutual Recognition Agreement for various reasons. Demography certainly plays a factor: with respective populations of 63 million in France versus 8 million in Quebec, more professionals cross the Atlantic Ocean towards Quebec than in the other direction. In addition, the recent profiles of both nations' economies-that is, a lingering recession in Europe and France and a relatively healthy economic perspective in Quebec-have further encouraged French professionals to consider working and living in Quebec. Finally, some professions in Quebec, in both the public and private sectors, expect (or already experience) labour shortages due to retirement; this has added another attractive incentive for new recruits.

\section{France-Quebec MRAs: Coming of age}

Following preliminary discussions between the French and Quebec governments, the official declaration of an Agreement for the Mutual Recognition of Professional Qualifications was announced on October 17, 2008. Former Premier Jean Charest and former President Nicolas

\footnotetext{
${ }^{1}$ A few associations supervise up to four professions, which explains why the number of professions is superior to the associations' number.

${ }^{2}$ Marie-Jeanne Blain, personal communication, September 26, 2013; Antoine Dumas-Martin, personal communication, September 17, 2013.
} 
Sarkozy convened to initiate this pioneering accord to further stimulate professional mobility between France and Quebec. Five principles were inscribed at the heart of the Agreement:

- service quality: maintaining the quality of services and professional work in both territories;

- proficiency in the French language;

- protecting the public, particularly the public's health and security;

- transparency, equity and reciprocity; and

- ensuring the efficiency of the process for the mutual recognition of professional qualifications.

One must also bear in mind that the MRAs target professionals trained and recognized as professionals in France, not necessarily those holding French citizenship. For example, although unlikely, a Kyrgyzstan citizen trained as a pharmacist in France could apply under the MRA to practice medicine in Quebec.

In Quebec, the professional system is regulated and monitored by Quebec's Board of Professions, which supervises the activities of 53 professions that are grouped into 45 professional organisations or orders ${ }^{3}$. This does not include trades (many in the construction area) nor financial sector services ${ }^{4}$ (mostly in financial and administrative areas). To name but a few, these professions range from engineers, doctors and lawyers, to accountants, social workers and architects. Upon the signing of the official France-Quebec Agreement, each profession's ruling body was given a few months to evaluate the feasibility of a mutual recognition arrangement (MRA) with its corresponding organisation in France. Once the possibility of an arrangement had been identified, the organisations had two years in which to create a MRA. As a result, out of 45 professional organisations in Quebec, as of writing, 26 eventually succeeded in formulating a MRA, and most within the two-year timeframe as specified in the official Agreement. During and after this initial period, a bilateral committee followed up on each organisation's advancement and helped to resolve any problems that arose during the process. This politically motivated Agreement thus played a fundamental role in bringing the responsible authorities to work together, so as to firstly define a timeline for meetings between each nation's professional organisations, and to secondly formulate conditions for professional recognition and access. At the end of the two-year period, most eligible professional organisations in Quebec had concluded a MRA with their counterparts in France. Although some organisations had not completely established their arrangement's terms, all had identified whether they could envision creating a MRA, and if so, the main questions to be clarified. As of February 2014, all eligible professional organisations had signed an arrangement. Furthermore, among these 26 professions, most had finished outlining the rules and by-laws detailing the process of entering into professional practice, as we will discuss below. Finally, a few professions are still establishing its rules (physiotherapists, for example); they could add up to the current 26 MRAs within the coming months.

Some professional organisations, however, came to conclude that a MRA would not be possible. This was reported to the bilateral committee, who accepted this conclusion. For over 20 professions it appeared impossible to reach an arrangement, for different reasons. In some

\footnotetext{
${ }^{3}$ See www.opq.gouv.qc.ca (in French). The Office des professions du Québec is mandated to protect the public by ensuring the quality of professionals' work, respect of standards, adequate governance, etc. ${ }^{4}$ The French term used is fonctions, which in this could be awkward to translate into "functions". It is thus differentiated from professions or trades. It includes insurance and financial brokers, for example.
} 
cases, no corresponding organization existed in France. In the absence of such a partner, it was concluded that a MRA could not be envisioned. Other professional organisations acknowledged that the gap between the profession's practice in the two nations was too wide to allow for an eventual MRA.

After the general Agreement, these arrangements constituted the first steps by describing the contents of initial training curricula and the contexts of professional practice. This comparative description led to the identification of common grounds, gaps and differences between the two jurisdictions' initial training contents and professional practice contexts. It is important to note that this analysis included both the content of initial training curricula and the context of professional practice. The resulting MRA could then address the differences between professionals' qualifications in each jurisdiction, in terms of both academic credentials and the nature of their work.

Therefore, after this two-year period, almost all of the 26 professions had reached an arrangement, some had started creating one but needed more time, and some among the 26 professions were already working on the next step. This unprecedented effort led professional organisations to clarify their needs for creating an effective, operational gateway through which professionals would access the host country's labour market faster. By 2012, most had concluded such arrangements. As of today, all organisations have concluded such an arrangement.

\section{Regulating access to the profession}

The next step involved creating a set of regulations that would specify the exact terms for different scenarios of complementary training, in order for migrants to eventually obtain full access to professional practice in Quebec. This step involved discussions not only with the French counterparts, but also with a wider array of institutions, mainly educational institutions. These important actors needed to be included in the process, in order to define a specific curriculum geared towards different types of professionals initially trained in France and possessing French-based experience.

This process includes recognition of academic requirements in the first step (the agreement), recognition of prior professional experience in the second step (regulations), and regulations defining the complementary measures required before accessing full professional practice. Each step involves a wide array of details and precise formulations, in order to cover the various individual situations that might arise when recognizing a professional's foreign credentials and experience.

The complexity of this process is intimately linked to two main features of professions: that they are monopolistic as well as accountable (Evetts, 2011, 2013). Professions tend to be monopolistic in that they hold a body of knowledge that is, by and large, agreed upon following a very normative process linked to a rational, deductive, scientific approach as a system of checks and balances about truth and fallacy. Consequently, this process ensures an authoritative claim to truth, or whatever second-best proposition holds the closest position to either an ultimate truth, or an agreed alternative in the supposed temporary absence of such a truth.

In Quebec, professionals are held accountable through a hybrid, state- and privately-supported legal system intended to protect the public (and indirectly, to protect the profession's reputation); they are primarily regulated by a professional organisation, which outlines the profession's rules of access, supervises professionals' work, and sanctions them for misconduct or incompetence. 
Because of the stakes involved (especially related to professional liabilities, whether in the medical, legal, engineering or social professions), this entire professional recognition process needs to be thoroughly alert to any act or behaviour of foreign origin which, in the host country's context, could prove the professional's incompetence.

\section{Language competence}

Since Quebec's official language is French, all professional organisations request that their members demonstrate their ability to work and communicate in French. Since on the Quebec side, MRAs between France and Quebec are aimed at professionals trained in France, those professionals obviously all possess competence in the French language. However, preliminary data has already demonstrated that a curious problem has arisen concerning this language requirement. Like most higher education institutions across the world, French universities encourage their students to study abroad for a semester or for a year, all the while respecting their university's academic requirements. But this means that some French professionals arrive in Quebec with less than three years of university training in French-a requirement that is stipulated in the engineers' MRA, for example. In the current state of regulations this question is being evaluated, to avoid unnecessarily zealous scrutiny and to still ensure equity with nonFrench candidates who may have been trained partly in a language other than French (usually English).

\section{On the length of the process}

From one profession to another, there are various steps involving varying lengths before a migrant professional obtains full access to practice in Quebec. Even within the same profession, each individual's distinct background and experience will result in a unique path to full professional access, involving shorter or longer periods of complementary training and assessment of their professional competence. Because transparency is valued, the rules and bylaws for each MRA are specified in detail, allowing candidates to evaluate the steps required (and the probable time delays) before entering full professional practice. However, the feasibility of evaluating the delays, steps, and documents required remains to be documented. Since many details are involved, one can expect that grey zones and problematic, unpredictable scenarios might appear. In addition, French professionals may initiate the first steps several months before migrating to Quebec, thereby rendering it difficult-from our point of view-to precisely evaluate the length of the entire process. What can be deduced, however, is the fact that the earlier a migrant sends their required documents, the quicker they are granted authorisation, leading to faster access to professional practice. For all professions, this first access phase is linked with some form of mentoring by a recognised member of a Quebec professional association.

In the case of engineers, the regulation concerning complementary training measures has only recently been implemented (July 2013). Engineers trained at a recognised educational institution (one of the "grandes écoles") in France receive a temporary and restrictive one-year permit to practice their profession in Quebec, which is twice renewable if needed. They are then asked to work for a full year under the supervision of an engineer who is a member of the Quebec Order of Engineers. Then they have to provide proof of three years' work experience as an engineer, including at least one year in Canada. If they come to Quebec without any prior experience, they have to accumulate three years of experience; this could be acquired in Quebec, under the supervision of a recognised colleague. Once these three years are completed, whether partially in France or elsewhere (but definitely including one year in Quebec), they can then take the professional order's admission exam (just as any other candidate would, whether native or 
immigrant). Passing that exam grants them full access to their professional practice as engineers under Quebec laws and rules. In the case of engineers, the Quebec-France MRA has built upon former agreements between Canada and other jurisdictions, such as under the Washington Accord. In developing the new MRA the engineers' associations were able to draw upon previous models; in most other professions, however, similar antecedents do not exist.

\section{The price of professionalism}

The academic and professional recognition of a migrant's prior experiences and credentials thus entails many steps, which take into consideration the differences that might arise when assessing individuals' unique professional profiles and formal training. It is therefore as much a consequence as a cause of this complexity, through which the organisation ensures continuity of its members' monopoly on its area of expertise.

The fees required at the various steps of professional recognition are also worth examining. Each profession confronts different legal and organisational challenges in evaluating a migrant's professional background. Such evaluations also take varying lengths of time and thus involve different resources. Nevertheless, a non-exhaustive review of information available online from several professional organisations shows that "opening a file" can cost from $\$ 225$ to $\$ 700$, which does not cover the costs of remedial training required. At this moment we do not yet have a global picture of total costs, from opening an initial file to the final steps of examinations (where such steps are required) and admission into the professional association. However, one can expect even greater cost variations among professions, since some professions might include more steps to full access (with cost variations within these), whereas other professions might not require the same steps. Cost variations can be justified at least in part through the presence of more costly infrastructure within some professions (such as those with labs or expensive training supervisors), but we still need to evaluate to what extent these cost variations can be attributed to profession-specific situations.

\section{Conclusion}

This article offers a primarily descriptive view of MRAs in Quebec, since we have yet to collect the data that would allow for a more thorough analysis. That is what we intend to do in our recently initiated research project, which examines individual migrants' access to professional practice in eight different professions. The main questions that arise from the description above are: how do individuals negotiate these regulations? How do they evaluate their trajectories after the fact? Is the principle of transparency effectively applied, in the experiences of professionals entering full professional practice? How do the length and costs of the various steps compare from one MRA to another? Beyond comparing, how do actors (professionals, associations, employers) evaluate these various steps? Finally, what can be suggested to improve migrant professionals' experiences of entering Quebec's professional environments?

Given the dearth of knowledge about the rapidly expanding cohorts of French professionals, there is no doubt that answers to these questions will illuminate this example of transnational professional practice and perhaps raise unexpected issues. For example, if the professional recognition process appears lengthy and costly, could migrant professionals be tempted by alternative employment opportunities in their new environment? Do migrant professionals stay in Quebec, or do they use the MRA as a springboard for accessing Canadian or American employment opportunities? The professionals involved would still fulfil the arrangement's objectives in terms of professional mobility, but perhaps not in their professional field. What if 
employers invite a professional to fill a position, thus bypassing the entire MRA scheme by placing the professional on a faster track, due to a lack of Canadian residents able to fill the position? As we can see, an in-depth analysis of individual migrants' access to professional practice in Quebec could yield many interesting results.

\section{References}

Chaix, A. (2012). "De l'entente France-Québec aux ententes internationales du Québec avec l'étranger : quel statut juridique ?", Communication at Conference Migrant workers: a transversal look at a complex reality, ACFAS, Montréal, May 8.

Evetts, J. (2013). "Profesionnalism: Value and Ideology", Current Sociology, 61 (5-6): 778-796.

Evetts, J. (2011). "A new professionalism? Challenges and Opportunities", Current Sociology, 59 (4): 406-422.

Houle, F. \& D. Roux (2012). "Le droit des professionnels et des gens de métier qui ont le statut de résident permanent de gagner leur vie au Québec en vertu de l'article 6 (2) (b) de la Charte canadienne des droits et libertés", Les Cahiers de Droit, 53 (1): 79-108.

Iredale, R. (2000). "Migration Policies for the Highly Skilled in the Asia-Pacific Region", International Migration Review, 34 (3): 882-906.

Korotkina, M. (2012). La reconnaissance des qualifications professionnelles comme condition à l'immigration au Québec ? Cadre juridique et enjeux politiques d'une réforme de procédure en amont. LL.M. dissertation, Law Faculty, University of Montreal.

Mercier, C. (2012). "The Quebec-France Agreement on the Mutual Recognition of Professional Qualifications", Journal of Nursing Regulation, 2 (4): 53-57.

Verdier, P.-H. (2011). "Mutual Recognition in International Finance", Harvard International Law Journal, 52: 56-108. 